\title{
Essential Considerations in Distance Education in KSA: Teacher Immediacy in a Virtual Teaching and Learning Environment
}

\author{
A. Al Ghamdi, A. Samarji, and A. Watt
}

\begin{abstract}
Teacher immediacy (verbal and non-verbal) remains an important factor towards prompting efficient pedagogical approaches. Whilst teacher immediacy in a classroom setting is important, there is growing awareness about the importance of the construct in a virtual setting as education shifts from explicit conventional face-to-face teaching and learning to a blended environment which includes distance education. This paper attempts to generate some understandings about the correlation between teacher immediacy, both verbal and non-verbal, and students' active participation and satisfaction in a distance education learning environment. This paper considers, in a preliminary research framework, a Saudi university which offers a range of distance education courses as an initial cohort from which to generate such understandings. Students' opinions, perceptions, and reported satisfaction were captured through utilising a structured questionnaire completed by 413 participants, enrolled in a variety of distance education courses offered by the aforementioned university. This study found that there was significant correlation between the overall adopted teacher immediacy (verbal and non-verbal) and students' overall online participation and satisfaction in the investigated distance education courses. In terms of gender differences, male participants have higher willingness to participate than female participants within the perceived immediacy behaviours. On the other hand, female participants were more satisfied in terms of communication than male participants within the perceived "e-immediacy" behaviours. These results serve as a prompt for further research on teacher immediacy in the rapidly developing and increasing virtual education domain in a global and connected world.
\end{abstract}

Index Terms-Distance education, teacher immediacy, e-immediacy, verbal immediacy, non-verbal immediacy, students' satisfaction, students' online participation, students' communication satisfaction.

\section{INTRODUCTION}

Teacher immediacy has been a topic of research and interest in conventional (face-to-face) classroom settings. Teacher immediacy- both verbal and non-verbal- focuses mainly on creating a close collaborative communicative environment, where immediacy as a term is defined as 'the relationship between the speaker and the objects he or she communicates about' [1]. A number of scholars perceived teacher immediacy as the reduction of psychological or

Manuscript received July 9, 2014; revised September 12. 2014

A. Al Ghamdi and A. Samarji are with College of Education, Victoria University, Australia (e-mail: abdullah.alghamdi2@live.vu.edu.au, ahmad.samarji@vu.edu.au).

A. Watt is with Victoria University Melbourne, Australia (e-mail: Anthony.Watt@vu.edu.au). physical distance between the teacher and students [2], [3]. As a consequence, immediacy results in psychological and physical closeness which promote effective communication between individuals [4]. Pedagogically, teacher immediacy promotes students' understandings and experiences [5] Recent research reported that university lecturers who employ immediacy - including lecturers' warmth and approachability- in their teaching and learning practice experience an increased level of students' participation and enjoy a greater 'breadth' of such participation [5]

In a digital and internationalised $21^{\text {st }}$ century, universities strive to reposition themselves into offering distance education [6]. In a virtual learning environment, physical separation is one of the characteristics of distance education. Regardless of the advantages physical separation might bring about (flexibility, savings, convenience, et al.), literature asserts that distance education students often experience a feeling of isolation and sometimes a sense of being neglected by their instructors [7], [8].

Recent research prompts for further investigation and generating deeper understanding about teacher immediacy and social presence [9], [10]. In other words, further research is needed to investigate the potential impact of the salience of both the instructor and the fellow students on student's participation, satisfaction, and acquisition of the essential and desired course capabilities. In this context, this paper will investigate through a preliminary study ${ }^{\mathrm{i}}$, the correlation between teacher immediacy, both verbal and non-verbal, and students' participation and satisfaction (communication satisfaction) in distance education offered by one of the Saudi universities. In this paper, the adopted and employed teacher immediacy behaviours via virtual settings (online courses), will be termed as "e-immediacy". The particular questions that this paper would like to investigate are:

- Are there any significant differences between female and male students' perceptions of teacher e-immediacy (verbal and non-verbal) and their online participation and communication satisfaction in the distance education program offered by a targeted Saudi university?

- Is there any correlation between verbal and non-verbal teacher e-immediacy and students' online participation and communication satisfaction in the distance education programs offered by a targeted Saudi university?

\section{LiterATURE REVIEW}

Historically, distance education, as defined by Michael Moore, occurs when the students and the teacher are 
separated by time and location, lacking face to face interaction and communication [11]. Distance education existed well before the introduction of Web 1.0 and Web 2.0 technologies over the past two decades [12]. In the $20^{\text {th }}$ Century, education through videotaped lessons and mail correspondence was deemed as a form of distance education.

For instance, in 1986, Charles Wedemyer of the University of Wisconsin started employing media in correspondence study and experimented with new technologies effective approaches for the delivery of distance education for his students [13]. Distance education has significantly developed in recent years in association with ICT developments [12], where online distance education enjoyed rapid growth and popularity as knowledge-based economy prompted and supported such flexible and cost-effective education approach [13], [14]. ICT through Web 2.0 technologies significantly transformed distance education, enabling a two-way interaction between the instructor and the students compared to the one mode delivery which was available through video, television, and Web 1.0 technologies [15]-[17].

In the USA, 'online enrolments have increased at rates far in excess of those of overall higher education' over the decade 2003-2013 [13]. In 2013, there was a reported increase of 570,000 enrolments in at least one online subject accumulating the total number of online enrolments to 6.7 million in the USA [18]. Distance education is inclined towards more growth in both the number of online courses offered and the number of students enrolling in these courses [18]-[20]. Additionally, many education institutions have been organising distance education courses as part of staff's professional development for their own employees and for external businesses and agencies [21]-[23].

The rapid development in the technologies employed in distance education has prompted research for more pedagogical support to associate such development in order to promote students' participation, understanding, and satisfaction in a virtual learning environment. Hence, in this context, this study focuses on teacher immediacy as an important supporting factor towards giving more pedagogical considerations to distance education.

In conventional face-to-face classroom settings, teacher immediacy is perceived between the speaker and the listener as a communication behaviour to enhance the sense of intimacy [24]. Teacher immediacy- both verbal and non-verbal- aims to enhance students' engagement and active participation in a process that they are major stakeholders of. In classrooms, teacher verbal immediacy comprises verbal messages and practices such as calling students by their first names, employing humour, and encouraging students to make a time and meet with the teacher if further assistance is required. Teacher non-verbal immediacy comprises body language and eye contact expressed by the teachers as they explain and move around in the classroom [8].

In a virtual online setting, teacher immediacy cannot enjoy the same aforementioned features in a face-to-face classroom setting due to the simple fact of physical and associated psychological separation between the teacher and the students in distance education. Teacher immediacy in online courses has been drawing the attention of a number of scholars due to its importance in supporting students' learning and easing the physical and psychological separation experienced in virtual settings [25], [26]. Teacher immediacy- both verbal and nonverbal- can be re-thought and contextualised for "online classrooms" through both synchronous and asynchronous communication modes. Research within the Transactional Distance (TD) Theory has rethought teacher immediacy in a distance education context. In an online setting, teacher immediacy includes teachers' timely response to students' messages and participation in asynchronous communication such as emails and discussion boards [1], [27]. The quickness of teacher's response to students through the various electronic communication means contribute to creating a sense of "online" closeness between the students and the teacher regardless of the many miles that might be separating them. However, in distance education, teacher immediacy such as eye contact, gestures, smiles, humour, praise, and personal recognition remains missing and can only be compensated by the perceived teacher immediacy [28]-[30]. The virtual environment in distance education- with the aid of technology- facilitates certain electronic gestures which contribute to promoting perceived teacher immediacy. Table I [31] lists few examples of both verbal and non-verbal teacher immediacy behaviours in an online teaching and learning environment. More online immediacy behaviours are highlighted in several studies [31]-[39].

\begin{tabular}{|c|c|c|}
\hline $\bar{N}$ & Verbal Immediacv Teacher & Example \\
\hline 1 & Initiating discussion & Story \\
\hline 2 & Asking questions & $\begin{array}{l}\text { Does anyone have answer the } \\
\text { question? }\end{array}$ \\
\hline 3 & Using humour & Funny Story or funny photos \\
\hline 4 & Using self-disclosure & $\begin{array}{l}\text { In the last weekend, I watched } \\
\text { this movie at the cinema }\end{array}$ \\
\hline 5 & Addressing students by name & Please Adam can you.... \\
\hline 6 & Using inclusive pronouns & you, your, we, our \\
\hline$N$ & Nonverbal Immediacv Teacher & Example \\
\hline 1 & Smiling & (3) \\
\hline 2 & Monotone voice & $\begin{array}{l}\text { italics or caps (WELL) } \\
\text { (GOOD) }\end{array}$ \\
\hline 3 & Vocal expressions & TODAY \\
\hline 4 & Gestures & \\
\hline 5 & Vocalization & $\begin{array}{l}\text { interjections in online } \\
\text { immediacy }\end{array}$ \\
\hline 6 & Animated moves & (6). \\
\hline
\end{tabular}

This paper is mainly informed by Moore's theory of Transactional Distance (TD), mainly Moore's notion that in distance education, the teacher and students are not only physically but also transactionally separated where avenues of communication, discussions, and interaction are limited or restricted [40]-[42]. As a result of the transactional separation, misunderstandings and communication gaps can arise in such teaching and learning situations [42]-[44]. The TD theory focuses on the types of discussion and interaction that are of use in such circumstances [45]. Currently, many researchers employ this theory (TD) to analyse distance education [46]-[48] and many others focus on the immediacy (or lack thereof) in distance education [31], [49]-[51]. TD theory is closely related to the concept of teacher immediacy because it explores the level of dialogue between the teacher and the student. In other words, the theory focuses on the social 
presence between the teacher and the student which is the core focus of teacher immediacy.

Research conducted supports the effectiveness of teacher immediacy in terms of:

- shortening the transactional distance between students and their teacher [52].

- increasing students-instructor interaction and exchange of ideas [53].

- enhancing communication that promotes better relationship and social well-being [44].

- improving instructor's perceived social presence through immediacy in online environment [54].

- improving students social life and appreciation of the learning system [55].

- improving educational instruction as immediacy provides better relationship between students and their teacher [56].

Focusing on teacher immediacy in reducing the impact of physical and psychological separation and promoting social presence in a virtual education setting contributes towards increasing distance education credibility and effectiveness as an alternative/complementary education setting to conventional face-to-face classroom education [57], [58]. Consequently, research on immediacy in online teaching and learning environments contributes to transforming the human-machine (technology) attention in distance education to the human-human relation facilitated by technology.

Saudi higher education institutes are no exception to other universities worldwide in focusing on and investing into distance education. In Saudi Arabia, distance education plays a vital role in facilitating the delivery of a number of online courses to students in regional areas, where attending the university campus is problematic to many of them. Hence, e-learning and online courses in Saudi Arabia are receiving much attention and investment from both the Saudi Ministry of Higher Education and Saudi universities. However, very little is researched and published on e-learning and distance education in a Saudi context. Therefore, this study aims to contribute to the distance education literature in general and the Saudi literature on this topic in particular. The study will investigate the potential impact of immediacy (both verbal and non-verbal) on students' online participation and students' satisfaction, where satisfaction in the context of this study refers to students' satisfaction with their engagement and communication levels with their teacher in a virtual setting.

\section{RESEARCH DESIGN}

The research methodology adopted in this study is a cross sectional questionnaire design incorporating a purposive sample. The sample who participated in this preliminary study comprised undergraduate male and female students who were enrolled in online courses from various majors (e.g history, mathematics, sciences, English literature, Islamic studies, etc) in one of the Saudi universities. The students were invited to participate via email invitations that included information about the study, consent forms, and a web-link to the questionnaire via the Survey Monkey Website (SMW). Invitations to participate were sent to the entire cohort of students enrolled in distance education courses at the targeted university (612 students), of which 413 students agreed to participate and completed the questionnaire. In terms of gender distribution, 296 female versus 117 male students participated in the questionnaire.

The observed immediacy behaviours employed by the teachers in the online courses, the subject of this study, were mainly:

- using humor and addressing students by name for VIB

- adopting all-capital style in certain words (e.g."GOOD”), using several emotions as acronyms (e.g. "LOL" for "laughing out loud"), employing punctuation (e.g."'!!!”), and using interjections (e.g. "Wow!") for NVIB.

\section{SURVEY INSTRUMENT DESIGN}

The instruments of this study were compiled in an electronic survey developed within the SMW. The survey instrument in the preliminary study utilised self-reported measures to evaluate perceptions of teacher immediacy behaviours and the impact of these behaviours on students' experiences in online courses. Overall, four questionnaires were employed. The teacher e-immediacy measures involved two questionnaires. The first two questionnaires focused on investigating teacher immediacy behaviours, both verbal and non-verbal, as independent variables. The first questionnaire articulated questions that focused on verbal immediacy behaviour (VIBT), whereas the second questionnaire articulated questions that targeted nonverbal immediacy behaviour (NVIBT). These two questionnaires were informed by Farwell's model [31]. The verbal immediacy questionnaire aimed to measure teachers' verbal immediacy behaviour as reported by the participating students. While, the non-verbal questionnaire aimed to measure students perceptions of the virtual motion or transactions (e.g. emoticons) employed by the teachers as part of their non-verbal immediacy behaviour during online discussion boards, forums and email communication. The assessment of verbal and non-verbal immediacy behaviours was determined through responses on a five point Likert scale, that included the anchors of $1=$ never, $2=$ rarely, $3=$ occasionally, $4=$ often, and $5=$ very often.

The third and fourth questionnaires were based on two dependent variables relating to students' learning experiences in an online setting. The first dependent variable was students' reported online participation (OP). The third questionnaire which focused on this variable was informed by Fassinger's model [59] which attempts to measure the level of students' participation in a classroom. The OP questionnaire was completed through a self-report with a Likert Scale, where $0=$ Never, $1=$ rarely, $2=$ occasionally, 3 $=$ often and $4=$ very often. The second dependent variable was students' communication satisfaction (CS), where in the context of this paper, satisfaction of students was measured based on their communication satisfaction such as their satisfaction based on their ability to communicate with their teachers and share comments. The fourth questionnaire was based on Goodboy, Martin and Bolkan [60]which attempts to measure the level of students' communication satisfaction in a classroom. The questionnaire referring to this dependent 
variable was conducted through a seven Likert Scale, where $1=$ strongly disagree, $2=$ moderately disagree, $3=$ slightly disagree, $4=$ neutral, $5=$ slightly agree, $6=$ moderately agree and $7=$ strongly agree. Both the third and fourth questionnaires were re-contextualised to an online virtual setting.

\section{RESULT}

Independent samples t-test (Table III) were utilized to identify if significant differences existed within the dependent variables between genders. Results indicated there were no significant differences in the scores for VIBT between female and male participants; $t(411)=0.549, p$ $=.584$. These results indicate that gender does not have significant impact on VIBT perceptions. Similarly, for NVIBT, there were no significant differences in the scores between female and male participants; $t(411)=0.008, p$ $=.994$ However, in terms of OP, the analysis revealed significant differences in the scores between female and male participants; $t(411)=-17.003, p<.001$. T-test results also showed significant differences in the scores for CS between female and male participants; $t(411)=4.124, p<0.001)$.

The mean scores of the perceived VIBT and NVIBT between male and female participants were not in much variation. However, the mean scores for OP indicate that male participants have higher willingness to participate than female participants within the perceived immediacy behaviours. On the other hand, the mean scores for CS indicated that female participants were more satisfied in terms of communication than male participants within the perceived e-immediacy behaviours.

TABLE II: COMPARISON OF VIBT, NVIBT, OP AND SCS MEAN SCORES BETWEEN GENDER (FEMALE OR MALE STUDENTS)

\begin{tabular}{cccccc}
\hline & \multicolumn{2}{c}{ Female } & \multicolumn{2}{c}{ Male } & t-test \\
\hline Variables & M & SD & M & SD & $P$-Value \\
\hline VIBT & 2.99 & 0.63 & 3.03 & 0.66 & .584 \\
NVIBT & 2.82 & 0.59 & 2.82 & 0.64 & .994 \\
OP & 3.54 & 0.59 & 4.93 & 1.05 & .001 \\
SCS & 4.30 & 0.70 & 3.98 & 0.75 & .001 \\
\hline
\end{tabular}

TABLE III: CORRELATIONS BETWEEN INDEPENDENT AND DEPENDENT VARIABLES FOR BOTH MALES AND FEMALES

\begin{tabular}{lcccc}
\hline Variables & VIBT & NVIBT & OP & CS \\
\hline VIBT & & $.65^{* *}$ & $.62^{* *}$ & $.59^{* *}$ \\
NVIBT & $.67^{* *}$ & & $.85^{* *}$ & $.63^{* *}$ \\
OP & $.55^{* *}$ & $.57^{* *}$ & & $.81^{* *}$ \\
CS & $.23^{*}$ & $.25^{* *}$ & $.28^{* *}$ & \\
\hline
\end{tabular}

*. Significant at the .05 level (2-tailed). **. Significant at the .01 level

(2-tailed).

VIBT = Verbal Immediacy Behaviour Teacher

NVIBT = Nonverbal Immediacy Behaviour Teacher

$\mathrm{OP}=$ Students' Online Participation experience

$\mathrm{CS}=$ Students' Communication Satisfactions

The Pearson's Correlation Coefficient (r) was used to investigate relationships between teacher immediacy (verbal and non-verbal) - as the independent variables- and students' participation and satisfaction- as dependent variables- in distance education.

Table II presents the correlation results for female and male participants. Correlations for male participants are presented in the lower diagonal of the table and correlations for female participants are presented in the upper diagonal region.

Results indicate that female participants' responses have significant associations between all the variables at the .01 level (2-tailed) and .05 level (2-tailed). The correlation between these two behaviour immediacy variables was found to be positive and moderate. OP (dependent variable) and VIBT (independent variable) relationship was positive and moderate. However, the correlation between OP and NVIBT showed a strong positive relationship. The relationships between CS (dependent variable) and VIBT and NVIBT (independent variables) were positive and moderate.

For male participants, correlation results indicated that there were significant associations at the .01 level (2-tailed) and .05 level (2-tailed) between all the variables. The correlation between VBIT and NVIBT was found to be positive and moderate. The association between OP and VIBT and NVIBT was also positive and moderate. Although the relationship between CS and VIBT and NVIBT was statistically significant, the strength of the correlation between these variables was positive and weak for male participants.

\section{DISCUSSION}

The first research question of this study sought to investigate gender-related differences in terms of the four variables (VIBT, NVIBT, OP, and CS). In terms of the perceived e-immediacy behaviours- both verbal and non-verbal- no significant differences were found between male and female participants. Possible reasons for this lack of difference are not control gender such as female teacher with female student and similar for male participants and may refer to the culture differences between students and teacher. This pattern is similar to findings present by Violette [61] in which at Brevard College in North Carolina of the first year of college study participants demonstrated no differences in perceptions of immediacy (verbal and non-verbal) as an outcome of gender contrasts. Conversely, significant differences were identified when it comes to OP and CS. The reported differences between female and male participants in relation to OP and CS may refer to other factors which need to be considered such as the content of course, the ICT literacy skills of the instructor, interpersonal communication with students, social interaction preferences, and instructor's employed dialogue strategy with his or her students in the virtual classroom [62]. The study conducted by Velez and Cano [63] employed verbal and non-verbal immediacy behaviours result was not significant in gender differences while asserted that there was significant in students motivation as gender. Other factors which contribute to differences amongst students' perceived e-immediacy behaviours and their satisfaction and experiences are cultural, demographic, and personal [62]. Whilst these factors have not been covered by this research, future research is prompted to take these factors in the context of data collection, analysis, and discussion.

The second question in this study considered the 
relationship, teacher immediacy behaviours (both verbal and non-verbal) immediacy were significantly correlated with both students' online participation and communication satisfaction for both female and male participants. Previous studies found that the verbal and non-verbal immediacy behaviours of teachers have significant relationship with students' experiences [31], [64]. Hence, results from this study support this association. In addition, results of the current study are in line with Moore's [65] TD theory, where the employment of immediacy behaviours- verbal and non-verbal- by the teacher contribute to reducing the sense of distance and increasing the feeling of closeness between students and the teacher in distance education.

In sum, the mean scores of the perceived VIBT and NVIBT between male and female participants were not in much variation. However, the mean scores for OP indicate that male participants have higher willingness to participate than female participants within the perceived immediacy behaviours. On the other hand, the mean scores for CS indicated that female participants were more satisfied in terms of communication than male participants within the perceived e-immediacy behaviours.

This preliminary study aimed to create a general understanding of the e-immediacy culture existing in the online courses offered by the targeted Saudi university. Hence, the researcher did not control the employed verbal and non-verbal immediacy behaviours or assign students to classes on the basis of either their gender or the teacher's gender. However, the main study- of which this preliminary study is part- will control the verbal and non-verbal immediacy behaviours and for the instructors' and students' gender and accordingly will have both control and experimental groups for further analysis and cross-comparison.

\section{CONClusion}

In this study, the pedagogical importance of e-immediacy (both verbal and non-verbal) in terms of students' reported online participation and communication satisfaction has been considered and investigated. This study shows that there is moderate to strong positive correlation between students' online participation and communication satisfaction and their perceived e-immediacy behaviours- both verbal and non-verbal- adopted by their instructors. Such findings complement with the Transactional Distance Theory, where employed e-immediacy behaviours via the incorporation of up-to-date ICT tools can significantly contribute towards reducing the sense of transactional separation, promoting connectedness between students and teachers, and ultimately promote teaching and learning in virtual settings. Such findings are timely with more focus on distance education in Saudi Arabia and worldwide to complement conventional face-to-face classroom education and replace it where and when needed.

This study found that students' reported online participation and communication satisfaction were gender related. However, additional factors need to be considered to generate a comprehensive basis to explain this pattern.

Findings from this preliminary study are limited by the
Saudi cohort of participants enrolled in online courses in the targeted Saudi university. Another limitation is the absence of control and experimental groups in the methodology. Findings from this research are very significant to the Saudi context and contribute to the developing research, interest, and investment in e-learning and distance education in Saudi Arabia. Further research is prompted to investigate the various pedagogical perspectives of e-immediacy in distance education both in Saudi Arabia and worldwide.

Note: this study is part of a $\mathrm{PhD}$ research project that is sponsored by the Saudi Ministry of Higher Education.

\section{ACKNOWLEDGMENT}

The preliminary study reported in this paper is part of a larger research thesis ( $\mathrm{PhD}$ thesis) investigating the impact of teacher immediacy on students' experiences and learning outcomes in distance education.

\section{REFERENCES}

[1] B. Mehlenbacher, Instruction and Technology: Designs for Everyday Learning, The MIT Press, 2010.

[2] K. I. Khoo, "Impact of immediate faculty behaviors on the learning of Japanese undergraduates in a US distance education program: Immediacy in cross-cultural instructional communication," The Claremont Graduate University, 2010

[3] P. D. Bolls, A. Tan, and E. Austin, "An exploratory comparison of native American and Caucasian students' attitudes toward teacher communicative behavior and toward school," 1997

[4] S. G. Tinley, "Teaching with immediacy: A relational study of African American male high school students and their white female language arts teachers engaged in a journal dialogue," ProQuest, 2008.

[5] A. Roberts and D. Friedman, "The Impact of Teacher Immediacy on Student Participation: An objective cross-disciplinary examination," International Journal of Teaching \& Learning in Higher Education, vol. 25, no. 1, 2013.

[6] Y. Hébert, A. A. Abdi, and L. Ebook, Critical Perspectives on International Education, Springer, 2013.

[7] K. D. Bohnstedt, M. K. Jerome, D. A. Lojkovic, F. J. Brigham, and M. M. Behrmann, "Instructor interaction and immediacy behaviors in a multipoint distance educational environment: Using Technology to improve low-incidence teacher preparation," Journal of Special Education Technology, vol. 28, no. 4, 2013.

[8] R. S. Kidd and M. K. Stamatakis, "Comparison of students' performance in and satisfaction with a clinical pharmacokinetics course delivered live and by interactive videoconferencing," American Journal of Pharmaceutical Education, vol. 70, no. 1, p. 10, 2006.

[9] G. Cui, "Evaluating online social presence: an overview of social presence assessment," Journal of Educational Technology Development and Exchange, vol. 6, no. 1, 2013.

[10] D. E. Campbell, "The influence of teacher immediacy behaviors on student performance in an online course (and the problem of method variance," Teaching of Psychology, vol. 41, no. 2, pp. 163-166, 2014.

[11] K. Harry, M. John, and D. Keegan, Distance Education: New Perspectives, Routledge, 2013.

[12] M. G. Moore, Handbook of Distance Education, Taylor \& Francis, 2013.

[13] H. Bidgoli, The Internet Encyclopedia, John Wiley \& Sons, 2004.

[14] A. Szücs, A. Tait, M. Vidal, and U. Bernath, Distance and e-Learning in Transition: Learning Innovation, Technology and Social Challenges, Wiley, 2013

[15] G. R. Norman, C. Vleuten, and D. Newble, International Handbook of Research in Medical Education, Kluwer Academic, 2002

[16] M. Simonson and C. Schlosser, Quarterly Review of Distance Education: Research That Guides Practice, Information Age Pub Incorporated, 2008.

[17] S. Huffman, "Cases on building quality distance delivery programs: Strategies and experiences," Information Science Reference, 2011

[18] I. E. Allen and J. Seaman, "Changing course: Ten years of tracking online education in the United States," ERIC, 2013.

[19] M. W. Allen, "Michael Allen's 2012 e-learning annual," Pfeiffer, 2011.

[20] J. Herrington, T. C. Reeves, and R. Oliver, A Guide to Authentic e-Learning, Taylor \& Francis, 2010. 
[21] R. Kwan, J. Fong, and J. Lam, "Hybrid learning," presented at 4th International Conference, ICHL 2011, Hong Kong, China, August 10-12, 2011, Springer, 2011.

[22] R. C. Clark and R. E. Mayer, "E-learning and the science of instruction: Proven guidelines for consumers and designers of multimedia learning," Pfeiffer, 2011.

[23] S. Wheeler, Connected Minds, Emerging Cultures: Cybercultures in Online Learning, Information Age Pub Inc, 2009.

[24] L. K. Guerrero, J. A. DeVito, and M. L. Hecht, The Nonverbal Communication Reader, Waveland Press Lone Grove, IL, 1999.

[25] L. Shedletsky and J. E. Aitken, "Cases on online discussion and interaction: experiences and outcomes," Information Science Reference, 2010.

[26] H. A. Hartel, "Empowering online learning: 100+ activities for reading, reflecting, displaying, and doing-by curtis j. bonk and ke zhang," Teaching Theology \& Religion, vol. 13, no. 1, pp. 82-84, 2010.

[27] R. Mason and F. Rennie, E-Learning and Social Networking Handbook: Resources for Higher Education, Taylor \& Francis, 2008.

[28] M. Simonson, "Scientific rigor and distance education," Quarterly Review of Distance Education, vol. 10, no, 4, p. vii(2), 2009.

[29] K. A. Jernberg, "Students' perceptions of learner empowerment and involvement as functions of students' expectations of instructional technology use and nonverbal immediacy," 2008.

[30] M. J. W. Lee and C. McLoughlin, "Web 2.0-based e-learning: applying social informatics for tertiary teaching," Information Science Reference, 2010.

[31] C. L. Farwell, "Measurements of effective teaching in the traditional and online contexts: Teacher immediacy, student motivation, \& student learning," Western Illinois University, 2011.

[32] D. Mashek and E. Y. Hammer, Empirical Research in Teaching and Learning: Contributions from Social Psychology, Wiley-Blackwell, 2011.

[33] B. R. Beebe, "No laughing matter: Student perceptions of instructional use of humor in the college classroom," Dissertation, Capella University, Proquest, 2007.

[34] M. L. Houser, R. L. Cowan, and D. A. West, "Investigating a new education frontier: Instructor communication behavior in CD-ROM Texts - Do traditionally positive behaviors translate into this new environment?" Communication Quarterly, vol. 55, no. 1, pp. 19-38, 2007.

[35] S. E. Hoehl, "The relationship between transformational leadership and student educational outcomes as moderated by verbal and nonverbal immediacy," Dissertation/Thesis, 2008.

[36] M. L. Knapp and J. A. Hall, Nonverbal Communication in Human Interaction, Wadsworth Pub Co, 2009.

[37] P. L. Witt and J. Kerssen-Griep, "Instructional feedback I: The interaction of facework and immediacy on students' perceptions of instructor credibility," Communication Education, vol. 60, no. 1, pp. 75-94, 2011.

[38] M. Kucuk, "Teacher immediacy behaviors and participation in computer mediated communication," Turkish Online Journal of Distance Education, 2009.

[39] V. Chidambaram, Y. H. Chiang, and B. Mutlu, "Designing persuasive robots: how robots might persuade people using vocal and nonverbal cues," Book Designing Persuasive Robots: How Robots Might Persuade People Using Vocal ad Nonverbal Cues, pp. 293-300, 2012.

[40] J. Dron, Control and Constraint in e-Learning: Choosing When to Choose, Idea Group Pub., 2007.

[41] D. Keegan, Theoretical Principles of Distance Education, Taylor \& Francis, 2013.

[42] C. E. Kasworm, A. D. Rose, and J. M. Ross-Gordon, Handbook of Adult and Continuing Education, SAGE Publications, Incorporated, 2010.

[43] D. Keegan, Theoretical Principles of Distance Education, Routledge, 1993.

[44] C. Wankel and P. Blessinger, Increasing Student Engagement and Retention in e-Learning Environments: Web 2. 0 and Blended Learning Technologies, Emerald Group Publishing, 2013.

[45] M. G. Moore, "2 Theory of transactional distance," Theoretical Principles of Distance Education, p. 22, 1993.

[46] L. Goel, P. Zhang, and M. Templeton, "Transactional distance revisited Bridging face and empirical validity," Computers in Human Behavior, 2012.

[47] R. Aluko, J. Hendrikz, and W. Fraser, "Transactional distance theory and total quality management in open and distance learning," Africa Education Review, vol. 8, no. 1, pp. 115-132, 2011.

[48] J. P. Shaw and J. Chen, "Transactional distance and teaching presence in e learning environments," International Journal of Innovation and Learning, vol. 11, no. 1, pp. 44-59, 2012.

[49] C. Baker, "The impact of instructor immediacy and presence for online student affective learning, cognition, and motivation," The Journal of Educators Online, vol. 7, issue 1, pp. 1-30, 2010.

[50] S. Ni and R. Aust, "Examining teacher verbal immediacy and sense of classroom community in online classes," International Journal on e-Learning, vol. 7, no. 3, pp. 477-498, 2008.

[51] M. P. Korres, T. Karalis, P. Leftheriotou, and E. G. Barriocanal, "Integrating adults' characteristics and the requirements for their effective learning in an e-learning environment," Best Practices for the Knowledge Society. Knowledge, Learning, Development and Technology for All, pp. 570-584, 2009.

[52] A. S. Gibby, "Student perceptions of interaction in an online foreign language learning environment," 2007.

[53] M. D. Lytras, P. O. D. Pablos, and E. Damiani, "Best practices for the knowledge society-knowledge, learning, development and technology for all," in Proc. Second World Summit on the Knowledge SocietWSKS 2009, Chania, Crete, Greece, September 16-18, 2009, Springer-Verlag New York Inc..

[54] Y. Tao, "The relationship between motivation and online social presence in an online class," 2009

[55] S. P. Ferris and S. H. Godar, Teaching and Learning with Virtual Teams, Information Science Publishing, 2006.

[56] M. Orey, R. M. Branch, and V. McClendon, Educational Media and Technology Yearbook, Libraries Unltd Inc., 2006.

[57] D. M. McInerney and S. V. Etten, Research on Sociocultural Influences on Motivation and Learning, Information Age Pub., 2002.

[58] C. M. Simpson, "Distance education at a U.S. public, land grant institution: A case study of faculty reward for junior faculty who teach via distance," University of Michigan, 2009.

[59] P. A. Fassinger, "How classes influences students' participation in college classroom," Journal of Classroom Interaction," vol. 35, pp. $38-47,2000$.

[60] A. K. Goodboy, M. M. Martin, and S. Bolkan, "The development and validation of the student communication satisfaction scale," Communication Education, vol. 58, no. 3, pp. 372-396, 2009.

[61] J. L. Violette, "Immediately clarifying classroom interactions: An examination of teacher immediacy, teacher clarity, teacher gender, and student gender on student affective, cognitive, and behavioral learning," University of Kentucky, 2002.

[62] T. P. Mottet and S. A. Beebe, "Relationships between teacher nonverbal immediacy, student emotional response, and perceived student learning," Communication Research Reports, vol. 19, no. 1, pp. 77-88, 2002.

[63] J. J. Velez and J. Cano, "The relationship between teacher immediacy and student motivation," Journal of Agricultural Education, vol. 49, no. 3, pp. 76-86, 2008.

[64] K. M. Torrens and J. A. Amador, Taking Your Course Online: An Interdisciplinary Journey, N.C.: Information Age Publishing, 2012.

[65] M. Moore and M. Thompson, "The effects of distance learning," ACSDE Research Monograph, vol. 15, 1997.

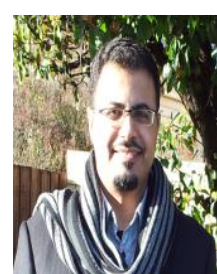

education.
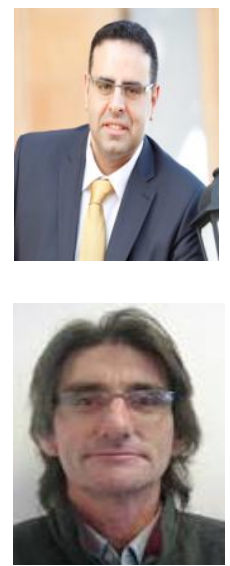

Abdullah Al Ghamdi is a PhD candidate at the College of Education, Victoria University, Melbourne. His PhD research focuses on the topic of technology in education. He received his master of education in e-learning from La Trobe University. Additionally, he is a secondary school teacher in Arabic language in the capital city of Saudi Arabia. His future research interest is in distance education, blended learning and ICT in

Ahmad Samarji is an academic at the College of Education, Victoria University Melbourne. Dr Samarji's diverse expertise and interests in education include: ICT in Education (ICTE) and e-learning, STEM education, forensic science and forensic medicine education, internationalisation of the curriculum, higher education role in knowledge management.

Anthony Watt is a senior lecturer of physical education at Victoria University. His research work is in the areas of the design and development of assessment instruments in sport psychology, student engagement in physical education, and childhood physical activity. His teaching focuses on the key practices associated with the teaching of physical education at the primary and secondary school levels. 